\title{
Optimization of welded square cellular plates with two different kinds of stiffeners
}

\author{
József Farkas ${ }^{1}$, Károly Jármai \\ ${ }^{1,2}$ University of Miskolc, H-3515 Miskolc, Hungary, \\ ${ }^{1}$ Professor emeritus, Dr.sci.techn. altfar@uni-miskolc.hu \\ ${ }^{2}$ Professor, Dr.sci.techn., corresponding author Tel: +36-46-565111, Fax:+36-46-563399, e-mail: \\ altjar@uni-miskolc.hu
}

\begin{abstract}
Cellular plates are constructed from two face plates and a stiffener grid welded between them. It is shown that the square cellular plates can be calculated as isotropic ones. Therefore, the classic formulae for maximum bending moment and deflection, valid for isotropic plates, can be used. The stiffeners can be made from halved rolled I-profiles, or from welded T-sections. These two kinds of cellular plates are optimized, and their minimum volumes and costs are compared to each other. The comparison shows that the cellular plate with welded T-stiffeners is more economic.
\end{abstract}

Keywords: cellular plates, welded stiffened plates, fabrication cost calculation, economy of welded structures, structural optimization

\section{Introduction}

Stiffened plate is one of the most frequently used structural components in welded structures. They are used as load-carrying elements of ships, bridges, offshore platforms, roofs, etc. In stability problems of welded structures the effect of initial imperfections and residual welding stresses should be taken into account. Many papers have been dealt with the stability and calculation of this kind of structures $[1,2,3,4]$.

Two types of stiffened plates can be constructed: plate stiffened on one side (in the following briefly stiffened plate) and cellular plate. Cellular plates consist of two face plates and a grid of stiffeners welded between them. The cells produce a large torsional stiffness; thus, the cellular plates can be calculated as isotropic ones. Cellular plates have some advantages over stiffened ones as follows. (a) their torsional stiffness contributes to the overall buckling strength significantly, therefore, their dimensions (height and thickness) can be smaller, (b) their symmetry eliminates the large residual welding distortions, which can occur in stiffened plates due to shrinkage of eccentric welds. Therefore cellular plates can be cheaper than stiffened ones, as it will be shown in next section.

In their previous studies, the authors have designed cellular plates with halved rolled I-stiffeners $[5,6,7]$. In the present study, these rolled stiffeners are replaced by welded T-stiffeners. The comparison of the cellular plates with the two different kinds of stiffeners shows that using welded T-stiffeners significant savings in mass and cost can be achieved.

The formulae for the two kinds of stiffeners are nearly the same; thus, the formulae for halved rolled I-stiffeners are described and then the differences for welded T-stiffeners are given.

\section{Bending and torsional stiffness of a cellular plate}


The Huber's equation for orthotropic plates in the case of a uniform transverse load $p$

$$
B_{x} w^{\prime \prime \prime}+2 H w^{w \cdots}+B_{y} w^{\cdots \cdots}=p
$$

where the torsional stiffness of an orthotropic plate is

$$
H=B_{x y}+B_{y x}+\frac{v}{2}\left(B_{x}+B_{y}\right)
$$

$v$ is the Poisson ratio, $w$ is the deflection

The corresponding bending and torsional stiffnesses are defined as

$$
B_{x}=\frac{E_{1} I_{y}}{a_{y}} ; B_{y}=\frac{E_{1} I_{x}}{a_{x}} ; E_{1}=\frac{E}{1-v^{2}}
$$

for cellular plates

$$
B_{x y}=\frac{G I_{y}}{a_{y}} ; B_{y x}=\frac{G I_{x}}{a_{x}} ; G=\frac{E}{2(1+v)}
$$

where $E$ is the Young modulus, $G$ is the shear modulus,

$I_{\mathrm{x}}$ and $I_{\mathrm{y}}$ are the second moment of inertias in two directions,

$a_{\mathrm{x}}$ and $a_{\mathrm{y}}$ are the distances between stiffeners in two directions.

$$
H=B_{x y}+B_{y x}+\frac{v}{2}\left(B_{x}+B_{y}\right)=\frac{E_{1}}{2}\left(\frac{I_{y}}{a_{y}}+\frac{I_{x}}{a_{x}}\right)
$$

for plates of quadratic symmetry

$$
H=B_{x}=B_{y}
$$

Thus, the torsional stiffness of a cellular plate of quadratic symmetry equals to its bending stiffness.

\section{Bending moments and deflections}

Lee et al. [8] have solved the differential equation for rectangular orthotropic plates (Eq.1) supported at four corners by using a polynomial function.

They gave formulae for bending moments and deflections as a function of bending and torsional stiffnesses. In the case of a square cellular plate, the bending stiffnesses are equal to the torsional stiffness $\left(B_{x}=B_{y}=H\right)$ and the maximum bending moment is

$$
M_{\max }=0.15 p L^{2}
$$

and the maximum deflection is expressed by

$$
w_{\text {max }}=0.025 p_{0} L^{4} / B_{x}
$$




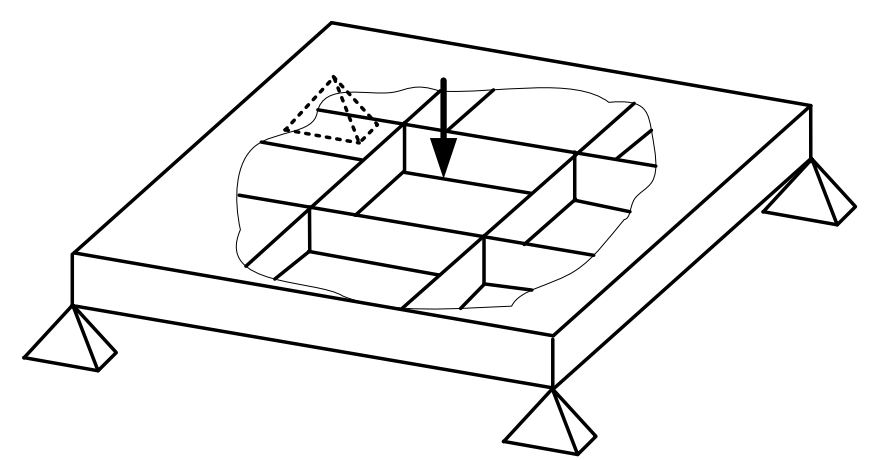

Figure 1. A cellular plate supported at four corners
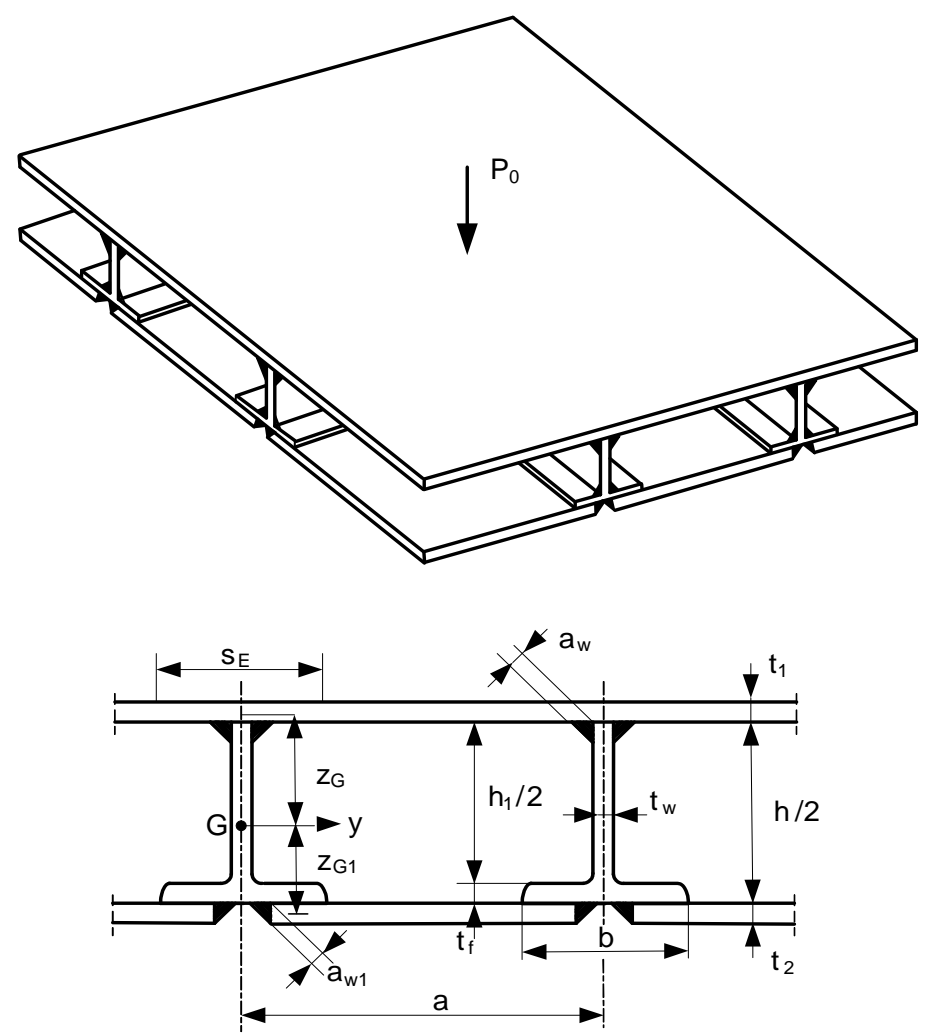

Figure 2. Cellular plate and dimensions of halved rolled I-section stiffener

where $L$ is the plate edge length, $p_{0}$ is the factored intensity of the uniformly distributed normal load and $p$ is the load intensity including the self mass of the plate.

Results for square isotropic plates according to Timoshenko \& Woinowsky-Krieger [9] for $v=0.3$ (they used a simple approximate energy model)

$$
M_{\max }=0.1404 p L^{2}
$$

and

$$
w_{\max }=0.0249 p_{0} L^{4} / B_{x}
$$

It can be seen that the constants are nearly the same.

\section{Cellular plate with halved rolled I-section stiffeners}




\subsection{Geometric characteristics (Fig. 2)}

The upper face plate parts can locally buckle from the compression stresses caused by bending. This local buckling is avoided by using effective plate widths according to Eurocode 3 [10]

$$
\begin{aligned}
& s_{e}=\rho s, s=\frac{a}{n} \\
& \rho=\frac{\lambda_{p}-0.22}{\lambda_{p}^{2}}, \lambda_{p}=\frac{s}{56.8 \varepsilon t_{1}}, \varepsilon=\sqrt{\frac{235}{f_{y}}}
\end{aligned}
$$

$n$ is the number of spacing, $f_{y}$ is the yield stress.

Cross-sectional area of a halved rolled I-section stiffener

$$
A_{S}=\frac{h_{1} t_{w}}{2}+b t_{f}, \quad h_{1}=h-2 t_{f}
$$

Cross-sectional area of a stiffener with upper and bottom base plate parts

$$
A=s_{e} t_{1}+a t_{2}+A_{S}, \quad a=\frac{L}{n+1}
$$

Distances of the centre of gravity

$$
\begin{aligned}
& z_{G}=\frac{1}{A}\left[a t_{2}\left(\frac{h}{2}+\frac{t_{1}}{2}+\frac{t_{2}}{2}\right)+b t_{f}\left(\frac{h_{1}+t_{1}+t_{f}}{2}\right)+\frac{h_{1} t_{w}}{2}\left(\frac{h_{1}}{4}+\frac{t_{1}}{2}\right)\right] \\
& z_{G 1}=\frac{h+t_{1}+t_{2}}{2}-z_{G}
\end{aligned}
$$

Moment of inertia

$$
\begin{aligned}
& I_{y}=s_{E} t_{1} z_{G}^{2}+a t_{2} z_{G 1}^{2}+b t_{f}\left(\frac{h_{1}+t_{1}+t_{f}}{2}-z_{G}\right)^{2}+I_{y 1} \\
& I_{y 1}=\frac{h_{1}^{3} t_{w}}{96}+\frac{h_{1} t_{w}}{2}\left(\frac{h_{1}}{4}+\frac{t_{1}}{2}-z_{G}\right)^{2}
\end{aligned}
$$

Bending stiffness

$$
B_{x}=\frac{E_{1} I_{y}}{a}, E_{1}=\frac{E}{1-v^{2}}
$$

Structural volumes corresponding to each fabrication phase are as follows: 


$$
\begin{aligned}
& V_{1}=L^{2} t_{1}, V_{2}=V_{2}+(n+2) A_{S} L, V_{3}=V_{2}+(n+2) A_{S} L \\
& V_{4}=V_{3}+L^{2} t_{2}
\end{aligned}
$$

Load intensity including the self mass

$$
p=p_{0}+\frac{\rho_{0} V_{4}}{L^{2}}
$$

\subsection{Design constraints}

Stress constraint including normal stress due to local bending of an upper base plate part with builtin edges according to Timoshenko \& Woinowsky-Krieger [9]

$$
\begin{aligned}
& \sigma_{P}=0.0513 \frac{p_{0} a^{2}}{t_{1}^{2} / 6}=0.3078 \frac{p_{0} a^{2}}{t_{1}^{2}} \\
& \sigma_{2}=\frac{0.15 p L^{2} z_{G}}{I_{y}}+\sigma_{P} \leq \frac{f_{y}}{1.1}
\end{aligned}
$$

Constraint on stress in the lower face plate

$$
\sigma_{1}=\frac{0.15 p L^{2} z_{G 1}}{I_{y}} \leq \frac{f_{y}}{1.1}
$$

Deflection constraint

$$
w_{\text {max }}=\frac{0.025 p_{0} L^{4}}{B_{x}} \leq w_{\text {allow }}=\frac{L}{300}
$$

Shear stress constraint at the corners

$$
\tau=\frac{p L^{2}}{4 h_{1} t_{w}} \leq \frac{f_{y}}{1.1 \sqrt{3}}
$$

\subsection{Fabrication constraints}

Thickness limitation: $t_{\min }=4 \mathrm{~mm}$.

Limitation of the distance between stiffener flanges to allow the welding of the stiffener web to the upper base plate:

$$
a-b \geq 300 \mathrm{~mm} \text {. }
$$

\subsection{Structural characteristics to be changed (variables)}

- number of stiffeners in one direction (square symmetry) $n$,

- thicknesses of the upper and bottom base plates $t_{1}$ and $t_{2}$, 
- height of the rolled I-section stiffener $h$.

Dimensions of UB profiles are given in Table 1. (ArcelorMittal Profile Catalogue [11])

Table 1 Selected UB profiles according to the ArcelorMittal catalogue

\begin{tabular}{ccccccc}
\hline UB Profile & $\begin{array}{c}h \\
\mathrm{Mm}\end{array}$ & $\begin{array}{c}b \\
\mathrm{~mm}\end{array}$ & $\begin{array}{c}t_{w} \\
\mathrm{~mm}\end{array}$ & $\begin{array}{c}t_{f} \\
\mathrm{~mm}\end{array}$ & $\begin{array}{c}A_{S} \\
\mathrm{~mm}^{2}\end{array}$ & $\begin{array}{c}I_{y} \times 10^{-4} \\
\mathrm{~mm}^{4}\end{array}$ \\
\hline $152 \times 89 \times 16$ & 152.4 & 88.7 & 4.5 & 7.7 & 2032 & 834 \\
\hline $168 \times 102 \times 19$ & 177.8 & 101.2 & 4.8 & 7.9 & 2426 & 1356 \\
\hline $203 \times 133 \times 25$ & 203.2 & 133.2 & 5.7 & 7.8 & 3187 & 2340 \\
\hline $254 \times 102 \times 25$ & 257.2 & 101.9 & 6.0 & 8.4 & 3204 & 3415 \\
\hline $305 \times 102 \times 28$ & 308.7 & 101.8 & 6.0 & 8.8 & 3588 & 5366 \\
\hline $356 \times 127 \times 39$ & 353.4 & 126.0 & 6.6 & 10.7 & 4977 & 10172 \\
\hline $406 \times 140 \times 46$ & 403.2 & 142.2 & 6.8 & 11.2 & 5864 & 15685 \\
\hline $457 \times 152 \times 60$ & 454.6 & 152.9 & 8.1 & 13.3 & 7623 & 25500 \\
\hline $533 \times 210 \times 92$ & 533.1 & 209.3 & 10.1 & 15.6 & 11740 & 55230 \\
\hline $610 \times 229 \times 113$ & 607.6 & 228.2 & 11.1 & 17.3 & 14390 & 87320 \\
\hline $686 \times 254 \times 140$ & 683.5 & 253.7 & 12.4 & 19.0 & 17840 & 136300 \\
\hline $762 \times 267 \times 173$ & 762.2 & 266.7 & 14.3 & 21.6 & 22040 & 205300 \\
\hline $838 \times 292 \times 194$ & 840.7 & 292.4 & 14.7 & 21.7 & 24680 & 279200 \\
\hline $914 \times 305 \times 224$ & 910.4 & 304.1 & 15.9 & 23.9 & 28560 & 376400 \\
\hline $1016 \times 305 \times 349$ & 1008.1 & 302 & 21.1 & 40.0 & 44420 & 722300 \\
\hline $1016 \times 305 \times 393$ & 1016.0 & 303 & 24.4 & 43.9 & 50020 & 807700 \\
\hline
\end{tabular}

\subsection{Numerical data}

Plate edge length: $L=18 \mathrm{~m}$, factored load intensity $p_{0}=150 \mathrm{~kg} / \mathrm{m}^{2}=0.0015 \mathrm{~N} / \mathrm{mm}^{2}$, yield stress of steel $f_{\mathrm{y}}=355 \mathrm{MPa}$, elastic modulus $E=2.1 \times 10^{5} \mathrm{MPa}$, Poisson ratio $v=0.3$, steel density $\rho=$ $7.85 \times 10^{-6} \mathrm{~kg} / \mathrm{mm}^{3}, \rho_{0}=7.85 \times 10^{-5} \mathrm{~N} / \mathrm{mm}^{3}$.

\subsection{Cost function}

The cost function is formulated according to the fabrication sequence [12].

(a) Welding of the upper base plate $(18 \times 18 \mathrm{~m})$ from 36 pieces of size $6 \mathrm{~m} \times 1.5 \mathrm{~m}$ using single or double bevel welds with complete joint penetration (GMAW-C gas metal arc welding with $\mathrm{CO}_{2}$ ):

$$
K_{w 1}=k_{w}\left[\Theta \sqrt{36 \rho V_{1}}+1.3 C_{1} t_{1}^{n 1} 13 L\right]
$$

welding cost factor $k_{w}=1 \$ / \mathrm{min}$, factor for the complexity of assembly $\Theta=3$,

for $t_{1}<15 \mathrm{~mm} C_{1}=0.1939$ and $n l=2$

for $t_{1}>15 \mathrm{~mm} C_{l}=0.1496$ and $n l=1.9029$.

Note that the cost factor $k_{w}$ varies between 0.5 and $2 \$ / \mathrm{min}$ for different countries and manufacturing companies, an average value of $1 \$ / \mathrm{min}$ is used.

(b) Welding of $n+2$ continuous stiffeners to the upper base plate by double fillet welds (GMAW-C) 


$$
K_{w 2}=k_{w}\left\lfloor\Theta \sqrt{(n+3) \rho V_{2}}+1.3 \times 0.3394 \times 10^{-3} a_{w}^{2} 2(n+2) L\right\rfloor
$$

$a_{w}=0.4 t_{w}$, but $a_{w \min }=4 \mathrm{~mm}$.

(c) Welding of $n+2$ intermittent stiffeners to the upper base plate and to the continuous stiffeners (webs with fillet welds, flanges with butt welds GMAW-C)

$$
\begin{aligned}
& K_{w 3}=k_{w}\left\lfloor\Theta \sqrt{\left(n^{2}+3 n+3\right) \rho V_{3}}+T_{1}+T_{2}\right\rfloor \\
& T_{1}=1.3 x 0.3394 x 10^{-3} a_{w}^{2}\left(h_{1}+b\right) 2(n+1)(n+2) \\
& T_{2}=1.3 C_{1} t_{f}^{n 1} 2 b(n+1)(n+2)
\end{aligned}
$$

(d) Welding of the bottom plate parts to the flanges of stiffeners by fillet welds (GMAW-C)

$$
\left.K_{w 4}=k_{w} \mid \Theta \sqrt{\left(n^{2}+2 n+2\right) \rho V_{4}}+1.3 \times 0.3394 \times 10^{-3} a_{w 1}^{2} 4 L(n+1)\right\rfloor
$$

$a_{w 1}=0.4 t_{2}$, but $a_{w 1 \min }=3 \mathrm{~mm}$.

Cost of material

$$
K_{M}=k_{M} \rho V_{4}, \quad k_{M}=1 \$ / \mathrm{kg},
$$

For $k_{M}$ the average value of $1 \$ / \mathrm{kg}$ is used.

Cost of painting

$$
K_{P}=k_{P} \Theta_{P} S_{P}, \Theta_{P}=3, \quad k_{P}=14.4 \times 10^{-6} \$ / \mathrm{mm}^{2}
$$

surface to be painted

$$
S_{P}=3 L^{2}+2 L\left(h_{1}+b\right)(n+2)
$$

The value of $k_{P}$ is given from literature.

Total cost

$$
K=K_{M}+K_{w 1}+K_{w 2}+K_{w 3}+K_{w 4}+K_{P}
$$

\subsection{Optimization and results}

A systematic search (evaluation of every combination between the realistic ranges of unknowns) for the optima is performed using a MathCAD algorithm. The results are given in Table 2. 
Table 2. Results of a systematic search. Halved rolled I-stiffeners. The optima are marked by bold letters. Allowed normal stress $\left(\sigma_{2}\right) 322 \mathrm{MPa}$, allowed deflection $w_{\max }=60 \mathrm{~mm}$. Dimensions in $\mathrm{mm}$

\begin{tabular}{cccccccc}
\hline$h$ & $n$ & $t_{1}$ & $t_{2}$ & $\sigma_{2} \mathrm{MPa}$ & $w_{\max } \mathrm{mm}$ & $V \times 10^{-9} \mathrm{~mm}^{3}$ & $K \times 10^{-5} \$$ \\
\hline 683.5 & 4 & 11 & 4 & 286 & 38 & 6.766 & 1.273 \\
\hline & 5 & 9 & 4 & 315 & 40 & 6.435 & 1.258 \\
\hline & 6 & 8 & 4 & 317 & 41 & 6.429 & 1.286 \\
\hline $\mathbf{6 0 7 . 6}$ & 3 & 13 & 4 & 311 & 49 & 6.791 & 1.253 \\
\hline & $\mathbf{4}$ & $\mathbf{1 1}$ & $\mathbf{4}$ & 316 & 50 & 6.400 & $\mathbf{1 . 2 2 4}$ \\
\hline & 5 & 10 & 4 & 302 & 50 & 6.332 & 1.240 \\
\hline & 6 & 9 & 4 & 302 & 51 & 6.265 & 1.258 \\
\hline 533.1 & $\mathbf{7}$ & $\mathbf{8}$ & $\mathbf{4}$ & 313 & 52 & $\mathbf{6 . 1 9 7}$ & 1.277 \\
\hline & 14 & 5 & 312 & 55 & 7.200 & 1.292 \\
\hline & 12 & 5 & 314 & 57 & 6.761 & 1.255 \\
\hline 5 & 11 & 5 & 298 & 57 & 6.646 & 1.263 \\
\hline 6 & 10 & 5 & 296 & 58 & 6.530 & 1.272 \\
\hline
\end{tabular}

\section{Cellular plate with welded $\mathrm{T}$-stiffeners}

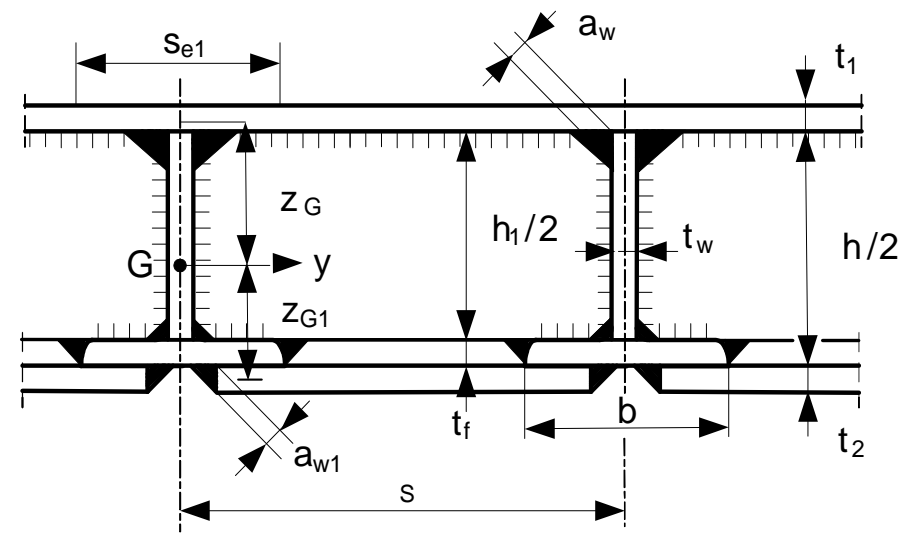

Figure 3. Cellular plate with welded T-stiffeners

\subsection{Geometric characteristics (Fig.3)}

The formulae of the characteristics of halved rolled I-section stiffeners are valid also for welded T-stiffeners with two differences: $b=30 \mathrm{~mm}$ and $t_{f}=t_{2}$.

\subsection{Buckling constraint for the stiffener web}

The web thickness should be taken to fulfil the following buckling constraint: according to Eurocode 3-1-5 for plates with varying longitudinal stress

$$
\frac{0.15 p L^{2} z_{G}}{I_{y}} \leq C_{x} f_{y}
$$

where

$$
C_{x}=1 \text { when } \bar{\lambda}_{p} \leq 0.673
$$




$$
\begin{aligned}
& C_{x}=\frac{\bar{\lambda}_{p}-0.055(3+\psi)}{\bar{\lambda}_{p}^{2}} \text { when } \bar{\lambda}_{p} \geq 0.673 \\
& \bar{\lambda}_{p}=\frac{h_{1} / 2}{t_{w}} \frac{1}{28.4 \varepsilon \sqrt{k_{\sigma}}}
\end{aligned}
$$

for $\quad-1 \leq \psi<0$

$$
\begin{aligned}
& k_{\sigma}=7.81-6.29 \psi+9.78 \psi^{2} \\
& \psi=-\frac{h_{1} / 2-z_{G}}{z_{G}}
\end{aligned}
$$

\subsection{Cost function}

In the cost function, the following changes are considered. Instead of Eqs $(31,32)$ the following formulae are used

$$
\begin{aligned}
& \left.K_{w 2}=k_{w} \mid \Theta \sqrt{(2 n+5) \rho V_{2}}+1.3 \times 0.3394 \times 10^{-3} a_{w}^{2} 4(n+2) L\right\rfloor \\
& K_{w 3}=k_{w}\left\lfloor\Theta \sqrt{\left(2 n^{2}+6 n+5\right) \rho V_{3}}+T_{1}+T_{2}\right\rfloor
\end{aligned}
$$

\subsection{Optimization and results}

The results of a systematic search are given in Table 3 .

Table 3. Results of a systematic search. Welded T-stiffeners. The optima are marked by bold letters. Allowed normal stress $\left(\sigma_{2}\right) 322 \mathrm{MPa}$, allowed deflection $w_{\max }=60 \mathrm{~mm}$. Dimensions in $\mathrm{mm}$

\begin{tabular}{cccccccccc}
\hline$h$ & $n$ & $t_{1}$ & $t_{2}$ & $t_{w}$ & $\sigma_{1} \mathrm{MPa}$ & $w \mathrm{~mm}$ & web buckling MPa & $V \times 10^{-9} \mathrm{~mm}^{3}$ & $K \times 10^{-5} \$$ \\
\hline 1400 & 4 & 7 & 4 & 6 & 309 & 12 & $187<201$ & 4.492 & 1.075 \\
\hline $\mathbf{1 3 0 0}$ & $\mathbf{5}$ & $\mathbf{6}$ & $\mathbf{4}$ & $\mathbf{6}$ & 320 & 16 & $204<215$ & $\mathbf{4 . 2 4 7}$ & 1.074 \\
\hline 1200 & 3 & 9 & 4 & 6 & 321 & 16 & $206<232$ & 4.877 & 1.073 \\
\hline $\mathbf{1 1 0 0}$ & $\mathbf{4}$ & $\mathbf{8}$ & $\mathbf{4}$ & $\mathbf{6}$ & 309 & 20 & $215<251$ & 4.622 & $\mathbf{1 . 0 6 8}$ \\
\hline 1000 & 5 & 7 & 4 & 7 & 317 & 24 & $232<310$ & 4.469 & 1.070 \\
\hline 900 & 4 & 9 & 4 & 5 & 311 & 26 & $237<258$ & 4.720 & 1.070 \\
\hline 800 & 5 & 8 & 4 & 7 & 322 & 37 & $258<375$ & 4.622 & 1.072 \\
\hline
\end{tabular}

\section{Comparison of the two optimized cellular plates with different stiffeners}

It has been shown in previous studies that, in the case of square symmetry, the torsional stiffness of cellular plates equals to their bending stiffness. Thus, they can be calculated as isotropic ones and the bending moments and deflection for a square plate supported at four corners can be obtained by using the formulae for isotropic plates.

In the optimization process the four variables are as follows: height and number of halved rolled Isection stiffeners, or T-stiffener as well as the thicknesses of upper and bottom face plates. A 
systematic search considers the constraints on stresses and deflection as well as the cost function to be minimized.

According to the results summarized in Tables 2 and 3 it can be concluded that the cellular plate with welded T-stiffeners is more economic, than that with halved rolled I-section stiffeners, since the mass is $(6.197-4.247) / 6.197 \times 100=31 \%$ smaller and the cost is $(1.224-1.068) / 1.224 \times 100=12 \%$ smaller. It is also shown, that the optima for cost and mass minima are different. It can be up to $10 \%$ saving in mass (volume).

\section{Acknowledgement}

The research was supported by the TÁMOP 4.2.4.A/2-11-1-2012-0001 priority project entitled 'National Excellence Program - Development and operation of domestic personnel support system for students and researchers, implemented within the framework of a convergence program, supported by the European Union, co-financed by the European Social Fund. The research was supported also by the Hungarian Scientific Research Fund OTKA T 109860 project and was partially carried out in the framework of the Center of Excellence of Innovative Engineering Design and Technologies at the University of Miskolc.

\section{References}

[1] Kwon YB, Park HS. Compression tests of longitudinally stiffened plates undergoing distortional buckling, Journal of Constructional Steel Research, 2011; 67(8): 1212-1224.

[2] Chacón R, Mirambell E, Real E. Transversally stiffened plate girders subjected to patch loading: Part 2. Additional numerical study and design proposal, Journal of Constructional Steel Research, 2013; 80: $492-504$.

[3] Sinur F, Beg D. Moment-shear interaction of stiffened plate girders - Numerical study and reliability analysis, Journal of Constructional Steel Research, 2013; 88: 231-243.

[4] Maiorana E, Pellegrino C, Modena C. Influence of longitudinal stiffeners on elastic stability of girder webs. Journal of Constructional Steel Research, 2011; 67(1): 51-64.

[5] Farkas J, Jármai K. Economic design of metal structures. Millpress, Rotterdam, The Netherlands. 2003. 397 p. ISBN 9077017755

[6] Farkas J, Jármai K. Design and optimization of metal structures. Horwood Publishing, Chichester, UK. 2008. 328 p. ISBN: 978-1-904275-29-9

[7] Jármai K, Farkas J. Cost calculation and optimisation of welded steel structures, Journal of Constructional Steel Research, 1999; 50(2): 115-135.

[8] Lee SL, Karashudi P, Zakeria M, Chan KS. Uniformly loaded orthotropic rectangular plate supported at the corners. Civil Engineering Transactions, Institution of Engineering Australia, 1971; 13(2): 101-106.

[9] Timoshenko S, Woinowsky-Krieger S. Theory of plates and shells. $2^{\text {nd }}$ ed. New York-Toronto-London: McGraw-Hill. 1959.

[10] Eurocode 3: Design of steel structures. Part 1-5: Plated structural elements. ENV 1993-1-5. (2007)

[11] ArcelorMittal Profile Catalogue, http://amsections.arcelormittal.com/fileadmin/redaction/4-Library/1Sales_programme_Brochures/Sales_programme/ArcelorMittal_EN_FR_DE.pdf (accessed November 2013)

[12] Farkas J, Jármai K. Optimum design of steel structures, Springer Verlag, Heidelberg, 2013. 288 p. ISBN 978-3-642-36867-7, http://dx.doi.org/10.1007/978-3-642-36868-4 